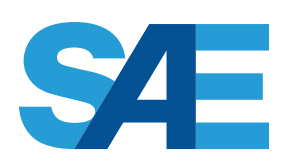

INTERNATIONAL

\title{
Optimisation of Alumina Coated Lightweight Brake Rotor
}

Abdulwahab A. Alnaqi

University of Leeds

\section{Suman Shrestha}

Keronite International Ltd.

\section{David C. Barton and Peter C. Brooks}

University of Leeds

CITATION: Alnaqi, A., Shrestha, S., Barton, D., and Brooks, P., "Optimisation of Alumina Coated Lightweight Brake Rotor," SAE Technical Paper 2014-01-2501, 2014, doi:10.4271/2014-01-2501.

Copyright @ 2014 SAE International

\begin{abstract}
Aluminium alloys have been used extensively in the automotive industry to reduce the weight of a vehicle and improve fuel consumption which in turn leads to a reduction in engine emissions. The main aim of the current study is to replace the conventional cast iron rotor material with a lightweight alternative such as coated aluminium alloy. The main challenge has been to meet both the cost and functional demands of modern mass-produced automotive braking systems. A sensitivity analysis based on the Taguchi approach was carried out to investigate the effect of various parameters on the thermal performance of a typical candidate disc brake. Wrought aluminium disc brake rotors coated with alumina on the rubbing surfaces were determined to have the best potential for replacing the conventional cast iron rotor at reasonable cost.
\end{abstract}

Optimisation of the structure was subsequently carried out using a genetic algorithm on the selected coated aluminium disc brake rotor. This determines the optimum thickness of the coating and the composition of the substrate based on selected criteria. Prototype aluminium disc brake rotors were coated with alumina using the Plasma Electrolytic Oxidation (PEO) technique and the thermal performance of these lightweight rotors was investigated experimentally using a brake dynamometer. A high speed thermal imaging system was used to evaluate and measure the rubbing surface temperature of the coated brake rotors. The experimental results showed generally good agreement with the numerical predictions. The coated wrought aluminium disc brake rotor was demonstrated to give good thermal and friction performance up to relatively high rubbing surface temperatures of the order of $500^{\circ} \mathrm{C}$.

\section{Keywords}

Disc brake, lightweight, aluminium, optimisation, brake dynamometer and thermal performance

\section{Introduction}

The automotive industry is under huge legislative pressure that requires vehicle emissions to be reduced. This has encouraged the automotive industry to find different ways to reduce vehicle mass by using lightweight material such as aluminium alloy. One of the areas which has recently received much attention is the replacement of the conventional cast iron disc with an aluminium alloy alternative $[\underline{1}, \underline{2}, \underline{3}, \underline{4}, \underline{5}, \underline{6}]$. A significant problem linked to the use of aluminium alloy discs lies in the overheating and softening of the material due to its low melting point which is of the order of $500^{\circ} \mathrm{C}[\underline{2}, \underline{6}, \underline{7}, \underline{8}]$.

The first passenger car to utilise aluminium metal matrix composite disc brake rotors was the Lotus Elise. The low vehicle mass of the Lotus Elise, which is $650 \mathrm{~kg}$ helped in achieving an acceptable performance of the disc brake rotor. However the main challenge is to use such a lightweight disc brake rotor in a mass produced small to medium passenger car. Using lightweight disc brake rotors made from materials such as aluminium alloy could reduce the weight of the traditional cast iron rotor by two thirds, typically $3 \mathrm{~kg}$ per rotor. In addition, aluminium disc brake rotors may offer other advantages such as reduction in brake judder and squeal [ 9 ].

Previous numerical and experimental investigations of lightweight disc brake rotors showed that an alumina coated wrought aluminium alloy has a better thermal and tribological performance than either coated or uncoated aluminium metal matrix composite [1, 2]. In addition, the production cost of a 
wrought aluminium alloy disc brake is much lower than that of the aluminium metal matrix composite. Also, axisymmetric thermal finite element analysis has been shown to be an efficient and accurate method of predicting the surface temperature of disc brake rotors during vehicle brake tests. The numerical model was validated against experimental results and demonstrated generally good agreement [2].

Many researchers have investigated the thermal performance of lightweight disc brake rotors using different methods [1, $\underline{3}, \underline{4}$, $\underline{5}, \underline{10}, \underline{11}, \underline{12}]$ but few of them have investigated their performance based on a formal optimisation analysis approach [6]. Taguchi defined the Design of Experiments (DOE) as a process for evaluating all possible combinations of parameters to reach the desired objective, both efficiently and reliably. Taguchi analysis has been used to find the effects of various disc brake parameters on the thermal performance which was then used to optimise the design of the lightweight disc brake rotor [6]. Since it would be too difficult to carry out numerical tests for every combination of the design variables, the meta-modelling technique is often used. This involves carrying out simulation analysis at certain sample points in the design space and fitting a sufficiently accurate response surface which is then utilised in the optimisation analysis [13].

In the current research, experimental and numerical studies were carried out to investigate the possibility of using coated wrought aluminium alloy rotors in road vehicles. The effect of vehicle mass on the peak rotor temperature was investigated numerically using the validated finite element model. A Taguchi study was undertaken to evaluate the effect of various design parameters on the thermal performance, and the outcome was used to carry out an optimisation analysis.

\section{Materials and Experimental Setup}

Small scale wrought aluminium alloy (6082-T6) disc brake rotors coated with alumina using the plasma electrolytic oxidation (PEO) process were considered in the current study. The small scale rotor and brake pad geometries are shown in Figure 1. Previous experimental results showed that the coated wrought aluminium alloy rotor had a better thermal and tribological performance than either coated aluminium metal matrix composite or plain aluminium alloy rotors [2]

The PEO coating applied to the plain aluminium rotors by the Keronite Company showed good adhesion between the coating and the substrate. The PEO coating was used to protect the aluminium alloy substrate by significantly improving the hardness of the surface and also acting as a thermal barrier layer [2]. The coating thickness was measured using an optical microscope and found to be around $50 \mu \mathrm{m}$. All surfaces of the rotors were coated with alumina by PEO process.

Both small and full scale brake dynamometers were used to assess the thermal performance of the coated aluminium alloy disc brake rotors and to validate the numerical model used in the optimisation analysis. The test rig and experimental methodology were explained in previous publications [1, 2, 4].

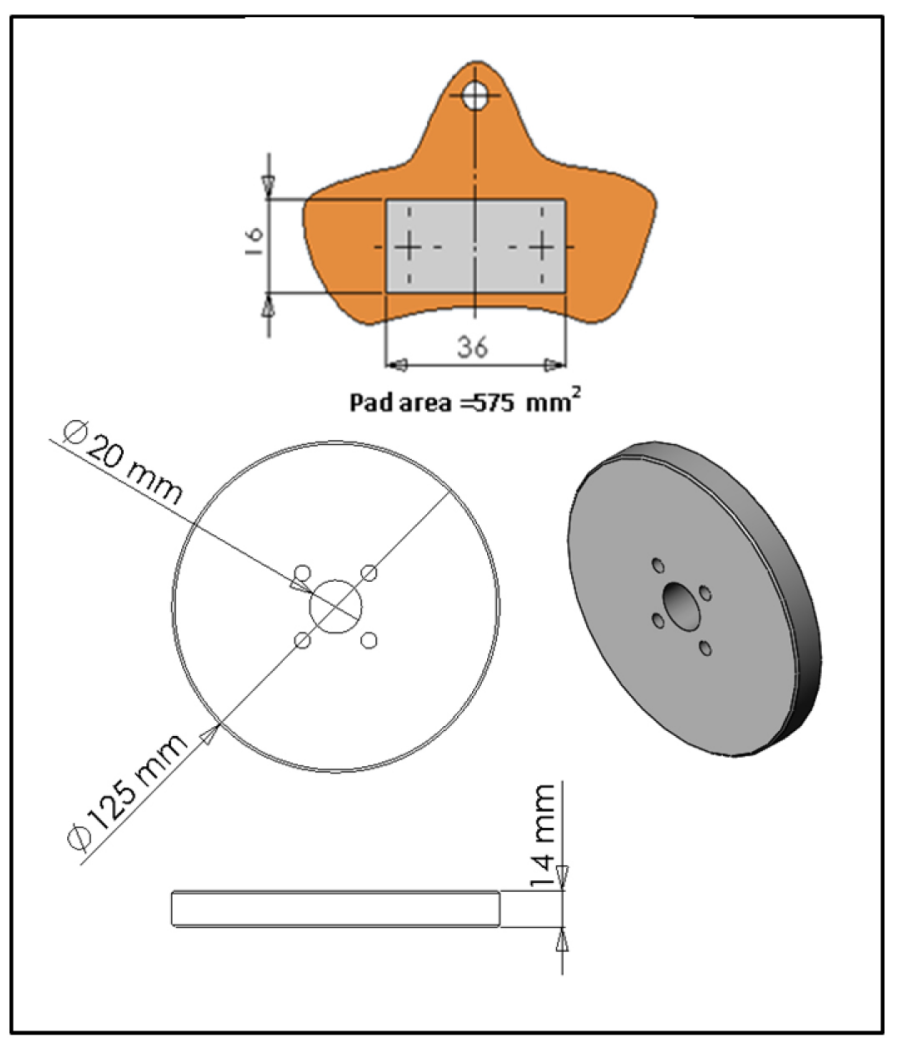

Figure 1. Small scale disc and pad geometries.

The surface temperature of the disc brake rotor was monitored using two sliding thermocouples as shown in Figure 2 and the pad temperature was monitored using an embedded thermocouples.

\section{Experimental Results}

The surface temperatures of the coated wrought aluminium disc brake rotor for the various braking tests conducted are shown in Figure 2. The test matrix was repeated several times with similar results thereby demonstrating repeatability. As shown in Figure 2, the surface temperature of the disc during Test 9 reached $500^{\circ} \mathrm{C}$ without any damage to the disc brake, the only change being a reduction in the coefficient of friction due to fade.

The coated aluminium disc was also tested under very extreme braking conditions in order to evaluate its maximum operating temperature. It was found that the disc did fail catastrophically when the surface temperature reached $550^{\circ} \mathrm{C}$. Figure 3 show the rotor immediately prior to melting and subsequent disintegration. Figure 4a shows the failed rotor and the intact coating shown in Figure 4b. 


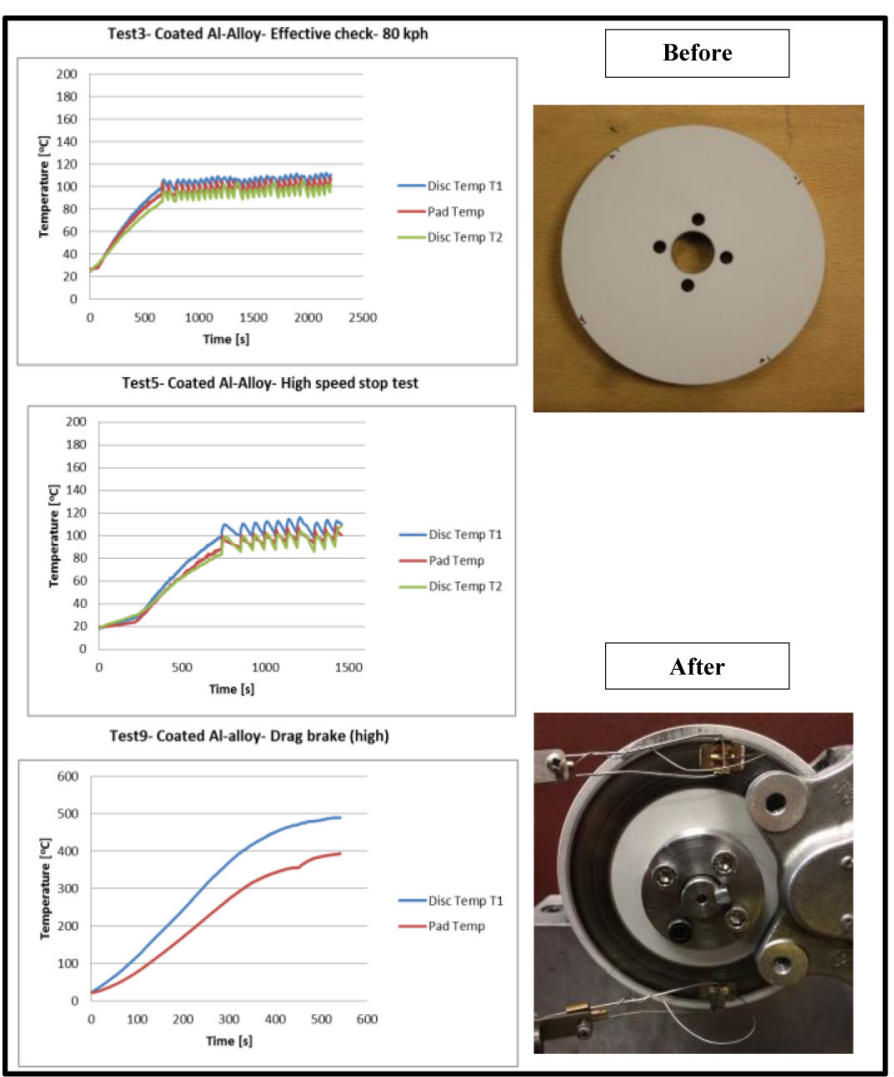

Figure 2. Surface temperature of the coated wrought aluminium alloy disc brake rotor.

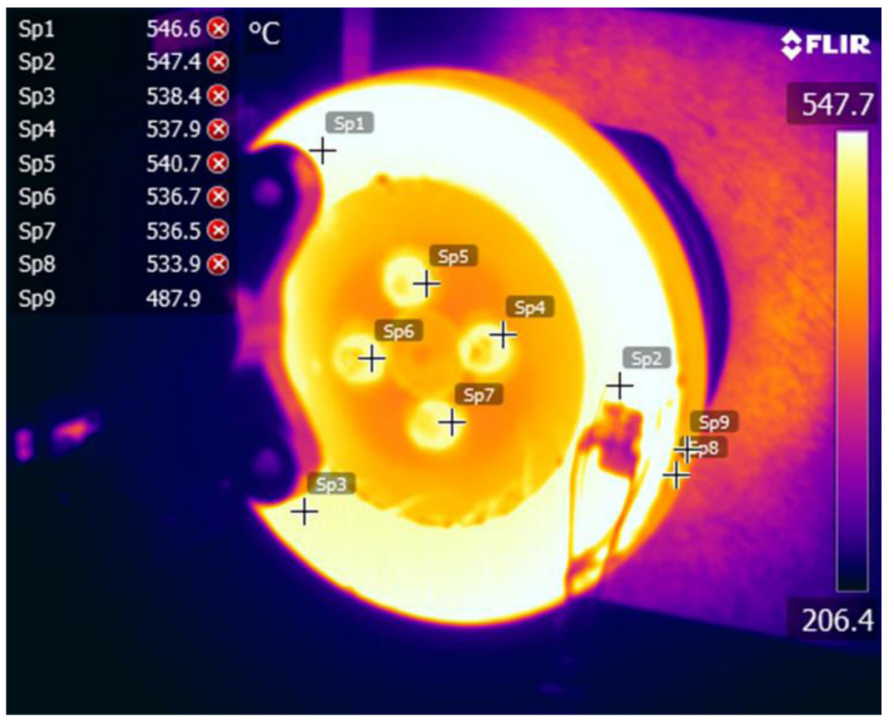

Figure 3. Temperature distribution of the coated wrought aluminium disc brake rotor before the catastrophic failure.

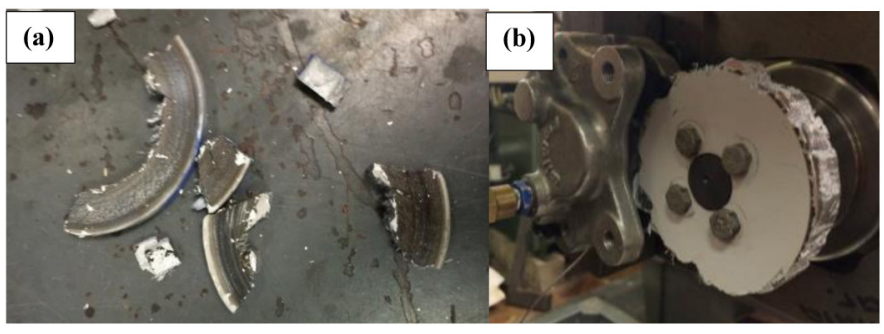

Figure 4. Coated wrought aluminium rotor after extreme braking test (a) disintegrated disc, (b) remaining central section of disc showing intact coating.

\section{Finite Element Models}

The finite element models used in this paper were analysed using implicit Abaqus software [14]. A two dimensional axisymmetric finite element model of the small scale disc was generated using quadrilateral heat transfer elements as shown in Figure 5. Symmetry conditions were applied at the centre plane of the disc to reduce the size of the model. The total number of elements in the model was 148050 with 150293 nodes. The coating was also modelled with a very fine mesh in order to see the effect on the surface temperature. In Figure 5 it is impossible to show the coating mesh as the coating thickness is only $50 \mu \mathrm{m}$ compared to the disc subtrate thickness which was $7 \mathrm{~mm}$. Convection heat loss was included in the model with an average convection coefficient of $40 \mathrm{~W} /$ $\mathrm{m}^{2} \mathrm{~K}$ applied to all free surfaces.

The coating was physically modeled in Abaqus and attached to the surface of the substrate using surface to surface contact with zero contact resistance. The highest thermal conductance allowed by Abaqus was used between the coating and the substrate. Uniform pressure distribution was assumed between the disc and pad.

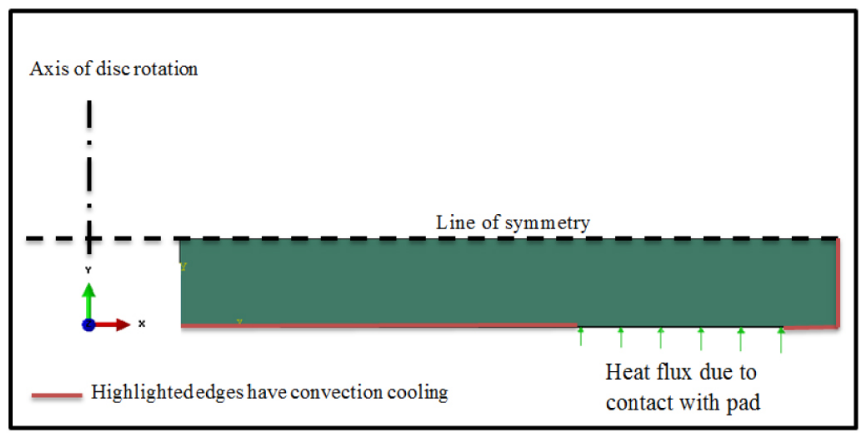

Figure 5. Finite element model of coated brake rotor.

The heat flux applied to the rubbing surfaces of the disc brake rotor was calculated based on knowledge of the scaling parameters between full size and small scale brake derived in previous work $[\underline{2}, \underline{3}, \underline{4}$ ]. The heat flux for the mountain descent was calculated using the equation:

$$
q=\frac{m g h x_{b}(1-p)}{4 A t}
$$

where $m$ is the mass of the vehicle, $x_{b}$ is the proportion of braking undertaken at the chosen axle, $h$ is the height dropped during the descent, $t$ is the time taken to descend the mountain, $p$ is the proportion of heat generated that is transferred to the pad and $A$ the area of one rubbing surface. Drag losses were neglected in the calculation of heat flux.

In the case of a high speed constant $g$ stop, the total heat flux was calculated using the following equation:

$$
q=\frac{m\left(v_{i}^{2}-v_{f}^{2}\right) x_{b}(1-p)}{8 A t}
$$


where $v_{i}$ and $v_{f}$ are the initial and final velocities of the vehicle respectively.

The partitioning ratio used in the current model was optimised based on the experimental results and it was found that $p=$ 0.07 gave the best overall agreement for the coated disc as shown in Figure 6 . This gave confidence in using the finite element model to simulate different braking conditions for the optimisation analysis.

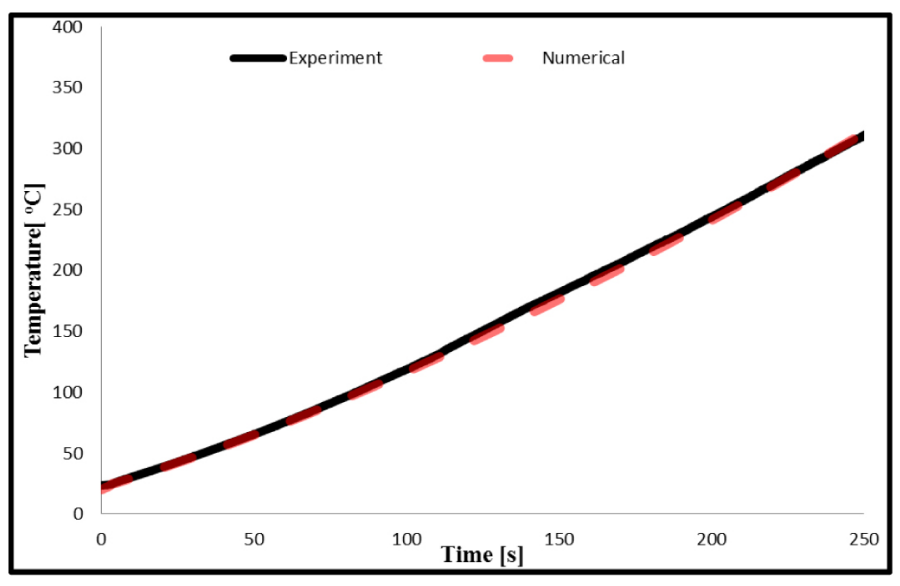

Figure 6. Numerical and experimental temperature response for coated aluminium alloy rotor.

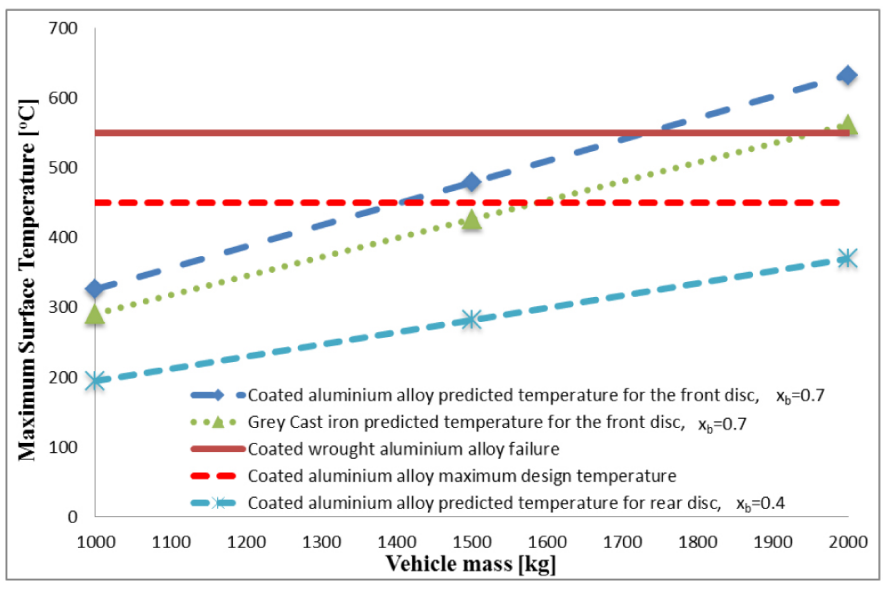

Figure 7. Effect of vehicle mass on the maximum temperature of the disc brake.

Based on the validated FE model, the effect of the vehicle mass on the maximum surface temperature of the coated brake rotor during a mountain descent was evaluated. The braking event selected for the current analysis was an extreme mountain descent lasting 23 minutes with an average slope of $12 \%$ and average vehicle speed of $80 \mathrm{~km} / \mathrm{h}$. The simulation results are shown in Figure 7 for both the coated aluminium alloy and standard grey cast iron discs. According to the experimental results the coated aluminium alloy disc brake rotor fails at $550^{\circ} \mathrm{C}$ surface temperature which implies a maximum vehicle mass of around $1700 \mathrm{~kg}$ for the front disc brake rotor for which $x_{b}$ has been set to 0.7 . However, to give an adequate safety margin, the maximum operation temperature of the coated aluminium alloy disc brake rotor was assumed to be $450^{\circ} \mathrm{C}$ which gives a maximum vehicle mass of $1400 \mathrm{~kg}$ for the front disc brake rotor. However the thermal performance of the coated front rotor could be further improved by optimising the disc design and the thermal properties of the disc materials which is considered in the following sections. The temperature response for a rear disc brake rotor was simulated for the same mountain descent as shown in Figure 7. To simulate the rear axle brake, the proportion of braking, $x_{b}$, was set to a realistic maximum of 0.4 . The results indicate that the coated aluminum alloy rotor could find application in a rear disc brake assembly on vehicles up to $2000 \mathrm{~kg}$ mass.

\section{Taguchi Study}

The initial investigation of the alumina coated aluminium disc brake rotor suggests that this concept is feasible for relatively low mass passenger vehicles. Improving the design and various other brake parameters could reduce the maximum surface temperature which would allow for a greater factor of safety or increase the allowable vehicle mass. The main problem is that the number of factors that need to be considered in order for the study to be valid would require a large number of numerical experiments. In order to simplify the proposed exercise, a Taguchi analysis was therefore considered to evaluate the relative influence of the different parameters.

The Design of Experiments approach was developed by Taguchi as a process for evaluating all possible methods of reaching a desired objective, both efficiently and reliably [15]. The Taguchi technique is widely used in design and manufacturing processes in order to find the optimum combination of parameters. Also, this technique allows the designer to assess the effect of various factors on the quality of the product. Taguchi defined the factors as either external or internal, where internal factors are those which can be modified by the designer and external factors are those which cannot be modified in a product [16].

An $L_{12}$ orthogonal array was used for the current investigation. Eight factors were selected to be studied at two levels, as defined in Table 1. The defined orthogonal array, which presents the number of simulation runs for each model with different combinations of factors and levels is shown in Table 2. This was used to investigate the effect of the different factors on the critical output which is the predicted maximum temperature of the disc.

In order to maximise the robustness of the exercise, the signal-to-noise $(\mathrm{S} / \mathrm{N})$ ratio was used to calculate the so-called "main effect" of each parameter. The main advantages of using the $\mathrm{S} / \mathrm{N}$ ratio are that it measures relative quality and is independent of the adjustment of the mean. It also reflects the variability in the response of a system caused by noise factors and does not introduce unnecessary complications [17]. The $\mathrm{S} / \mathrm{N}$ ratio was calculated from the following equation [16]:

$$
\frac{S}{N}=-10 \log _{10}(V)
$$

in which the variance $V$ is given by: 


$$
V=\frac{1}{N}\left(Y_{1}^{2}+Y_{2}^{2}+\cdots+Y_{N}^{2}\right)
$$

where $V$ is the variance, $N$ is the number of data points and $Y_{i}$ is the value of the $\mathrm{i}^{\text {th }}$ data point (i.e. in this case, the maximum disc temperature). The main effects were then calculated by finding the difference between the S/N ratio of level 1 and 2; the higher the value, the greater is the influence that the factor has on the maximum rotor surface temperature.

The brake event parameters selected for carrying out the Taguchi study were as follows: drag braking event for $10 \mathrm{~s}$, with a constant vehicle speed of $60 \mathrm{~km} / \mathrm{h}$ and an average slope of $12 \%$ with equivalent vehicle mass of $1400 \mathrm{~kg}$. The reason for not considering the full 23 minute of the extreme mountain descent is the very large computational time for each run.

Table 1. Factors selected for the Taguchi study with their maximum and minimum levels for the coated disc brake rotor.

\begin{tabular}{|c|c|c|c|}
\hline \multicolumn{2}{|c|}{ Factor } & \multicolumn{2}{c|}{ Level } \\
\cline { 3 - 4 } \multicolumn{2}{|c|}{} & 1 & 2 \\
\hline A & Disc thickness $(\mathrm{mm})$ & 5 & 15 \\
\hline B & Disc density $\left(\mathrm{kg} / \mathrm{m}^{3}\right)$ & 2700 & 3100 \\
\hline C & Disc thermal conductivity $\left(\mathrm{W} / \mathrm{m}^{2} \mathrm{~K}\right)$ & 90 & 240 \\
\hline D & Disc specific heat $(\mathrm{J} / \mathrm{kgK})$ & 800 & 900 \\
\hline E & Coating thickness $(\mu \mathrm{m})$ & 30 & 100 \\
\hline F & Coating density $\left(\mathrm{kg} / \mathrm{m}^{3}\right)$ & 2700 & 3200 \\
\hline H & Coating thermal conductivity $\left(\mathrm{W} / \mathrm{m}^{2} \mathrm{~K}\right)$ & 0.5 & 4 \\
\hline
\end{tabular}

Table 2. $\mathrm{L}_{12}$ Taguchi matrix.

\begin{tabular}{|c|c|c|c|c|c|c|c|c|c|c|c|}
\hline & \multicolumn{10}{|c|}{ Factor } \\
\hline Run & $\mathrm{A}$ & $\mathrm{B}$ & $\mathrm{C}$ & $\mathrm{D}$ & $\mathrm{E}$ & $\mathrm{F}$ & $\mathrm{G}$ & $\mathrm{H}$ & $\mathrm{I}$ & $\mathrm{J}$ & $\mathrm{K}$ \\
\hline 1 & 1 & 1 & 1 & 1 & 1 & 1 & 1 & 1 & 1 & 1 & 1 \\
\hline 2 & 1 & 1 & 1 & 1 & 1 & 2 & 2 & 2 & 2 & 2 & 2 \\
\hline 3 & 1 & 1 & 2 & 2 & 2 & 1 & 1 & 1 & 2 & 2 & 2 \\
\hline 4 & 1 & 2 & 1 & 2 & 2 & 1 & 2 & 2 & 1 & 1 & 2 \\
\hline 5 & 1 & 2 & 2 & 1 & 2 & 2 & 1 & 2 & 1 & 2 & 1 \\
\hline 6 & 1 & 2 & 2 & 2 & 1 & 2 & 2 & 1 & 2 & 1 & 1 \\
\hline 7 & 2 & 1 & 2 & 2 & 1 & 1 & 2 & 2 & 1 & 2 & 1 \\
\hline 8 & 2 & 1 & 2 & 1 & 2 & 2 & 2 & 1 & 1 & 1 & 2 \\
\hline 9 & 2 & 1 & 1 & 2 & 2 & 2 & 1 & 2 & 2 & 1 & 1 \\
\hline 10 & 2 & 2 & 2 & 1 & 1 & 1 & 1 & 2 & 2 & 1 & 2 \\
\hline 11 & 2 & 2 & 1 & 2 & 1 & 2 & 1 & 1 & 1 & 2 & 2 \\
\hline 12 & 2 & 2 & 1 & 1 & 2 & 1 & 2 & 1 & 2 & 2 & 1 \\
\hline
\end{tabular}

The maximum disc brake temperature and the $\mathrm{S} / \mathrm{N}$ ratios were calculated for the different combinations (shown in Table 2), with the results as shown in Table A1 and Table A2 respectively. The summary of these results in Figure 8 indicates that the substrate thickness has the largest effect and the substrate thermal conductivity the second largest effect. Overall the coating thickness has the smallest effect on the maximum disc brake temperature.
From this analysis it was found that the disc thickness is the main factor that has the largest effect on the maximum surface temperature. This is because the thermal inertia of the disc is directly related to its size. The coating thickness has the smallest effect on the maximum surface temperature but it is used in the following optimisation analysis as it has an influence on the cost and processing time. It is also a parameter that can be relatively easily controlled compared to the material properties of the alumina coating which are largely pre-determined.

Examination of Table A1 shows that run 7 gave the lowest maximum surface temperature. The factors selected for this run satisfy the best values recommended by the main effects shown in Figure 8, i.e. maximization of substrate thickness, maximisation of substrate thermal conductivity and maximisation of the coating thermal conductivity; therefore a confirmation run was not deemed necessary.

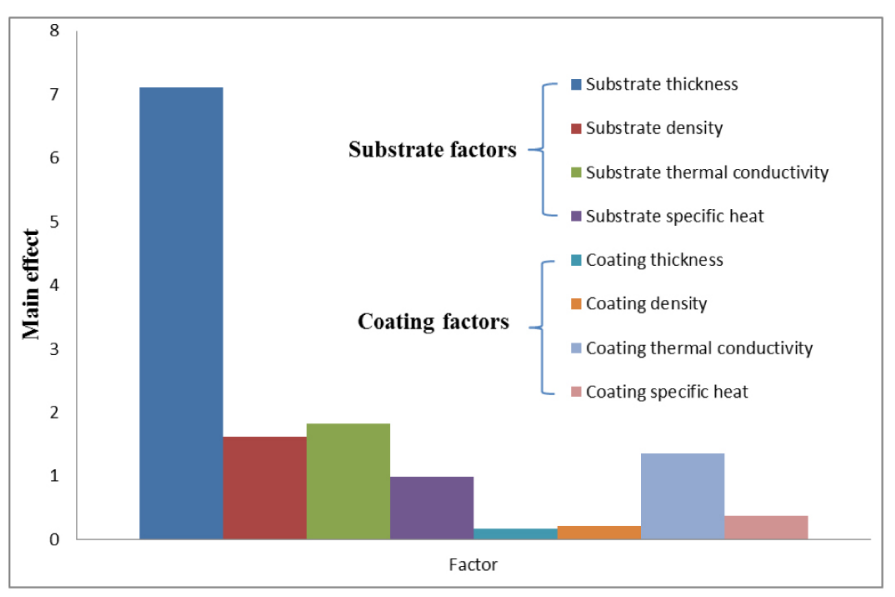

Figure 8. Main effects for the coated disc brake rotor.

\section{Optimisation Analysis}

The coated aluminium alloy disc has already been shown to have very good thermal and tribological performance. In this section, a genetic algorithm was used to investigate the optimum thickness of the coating and the disc brake substrate in order to further improve the thermal performance. The material properties assumed were similar to the material properties used in the previous analysis for the PEO coated wrought aluminium alloy (6082) disc brake rotor with the same overall geometry. The optimisation problem defined in the current section is to minimise the weight of the disc brake rotor by minimising the total thickness of the coating (tc) and substrate (ts) based on the following constraints: the maximum temperature at the surface of the coating must be less than $550^{\circ} \mathrm{C}$; the maximum temperature in the substrate must be less than $450^{\circ} \mathrm{C}$; the coating thickness must be in the range 30-100 $\mu \mathrm{m}$; and the disc thickness must be in the range 5-15 $\mathrm{mm}$. These parameters were selected based on material limitation and overall size constraints.

Determining the best combination of design variables located within the design space is a typical optimisation problem. In this case, two design variables were investigated: namely, coating thickness (tc) and substrate thickness (ts). Simulating 
every possible combination of even just these two variables would be far from straightforward, so in order to find the best combination, meta-modelling was used which provides an accurate set of results using the minimum number of experiments or simulations [13].

Here the Optimal Latin Hypercube (OLH) approach was used to produce 30 different combinations of the selected design variables. This approach distributes the design variables in the design space uniformly within the lower and upper limits of each variable. The selected OLH approach is a combination of two parts, which use build and validation models. The main advantage of the two model approach is that it maximises the uniformity of the variables in the design space.

The OLH building and validation points were generated uniformly by using the permutation genetic algorithm (PermGA) [13]. The two design variables were distributed uniformly through the space within the lower and upper limits to form 30 different combinations of building and validation points as shown in Figure 9 . The building points were used to construct the output response surface of the design variable. The validation points were used to ensure that the fitted response surface accurately reflect the system behavior and can therefore be used to carry out the optimisation exercise.

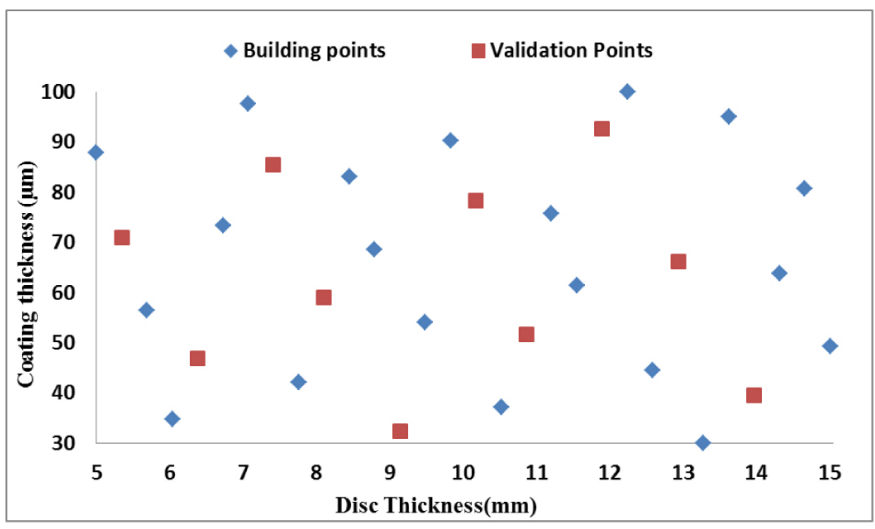

Figure 9. Building and validation points.

The axisymmetric transient finite element model for the coated wrought aluminium alloy disc brake rotor was used to simulate the 30 combinations using Abaqus software. The braking event selected for the simulation was as follows: high rate constant $\mathrm{g}$ stop with a vehicle speed of $205 \mathrm{~km} / \mathrm{h}$ and deceleration of $1 \mathrm{~g}$ for a vehicle mass of $1400 \mathrm{~kg}$. The main reason for choosing this braking event was to generate the maximum achievable surface temperature on the rotor with reasonable computational run time. The maximum surface temperature of the coating and the substrate was monitored throughout the simulation and used to obtain an approximate response within the design space using the moving least squares approximation method as shown for the coating and substrate maximum temperature in Figures 10 and 11 respectively. These results confirm that the substrate thickness has a much stronger influence on the surface temperatures of both the coating and substrate compared to the coating thickness. It shows that as the substrate thickness increased the maximum temperature for the substrate and coating decreases.

The optimisation problem was then solved using the genetic algorithm (GA) option of Hyperstudy v12 [18]. The main objective was to minimise both the coating and substrate thickness, thus reducing the total weight of the brake rotor, in accordance with the constraints defined previously. The results show that the optimum point that met all the constraints and the objective function was ts $=12.24 \mathrm{~mm}$ and tc $=30 \mu \mathrm{m}$ given a total disc thickness of $12.25 \mathrm{~mm}$. This design will be used in the following section to make sure that it meets the various braking application requirements. A comparison between the predicted optimum results and the simulation results for this particular design variable is shown in Table 3. It can be seen that the maximum temperatures for the coating and for the substrate predicted by the optimisation algorithm are very similar to those of the actual simulation which gives confidence in the validity of the latter algorithm.

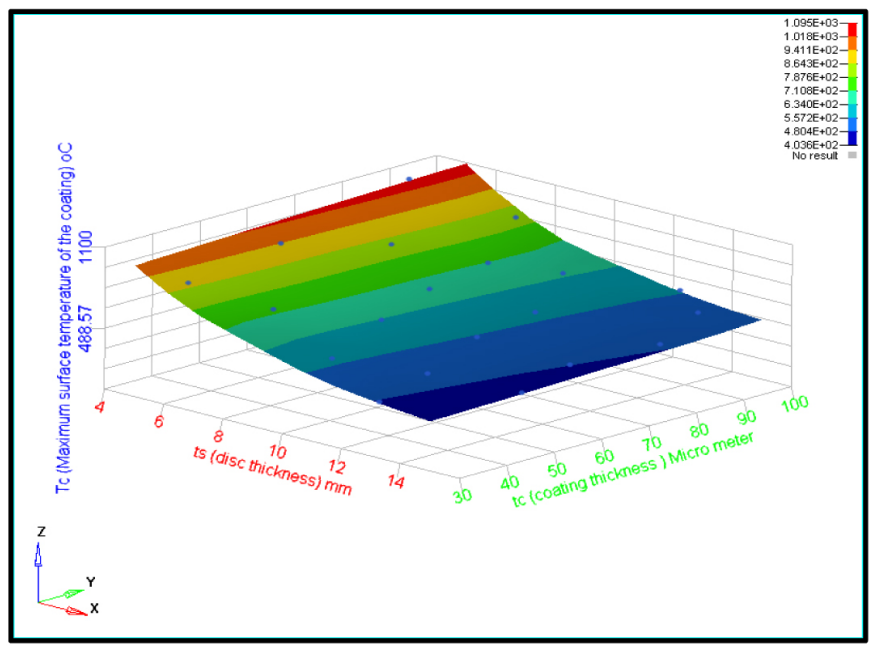

Figure 10. Response surface for the maximum surface temperature of the coating.

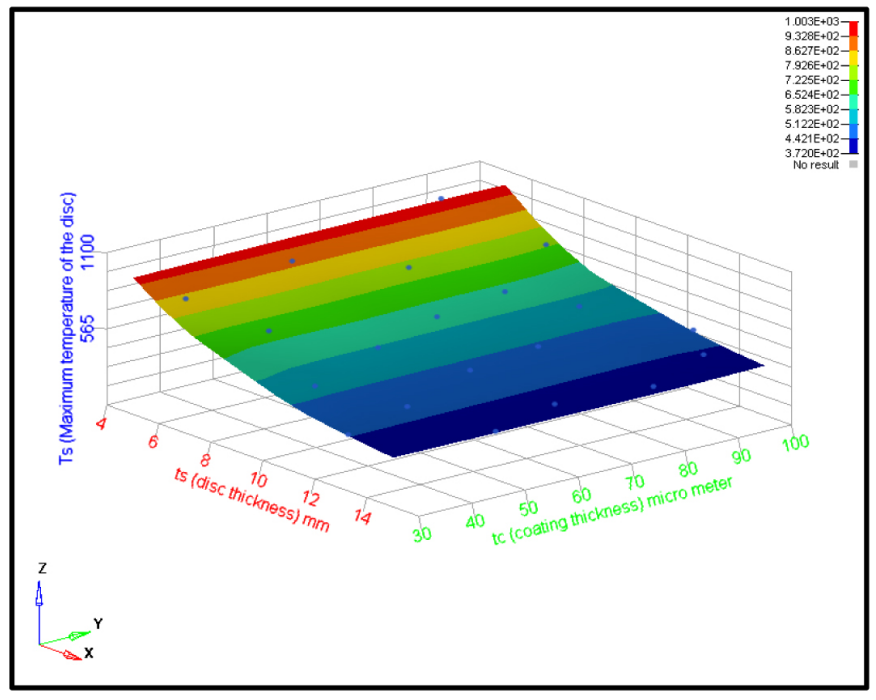

Figure 11. Response surface for the maximum temperature of the substrate. 
Table 3. Optimisation and actual simulation results.

\begin{tabular}{|c|c|c|c|c|c|c|c|}
\hline \multicolumn{2}{|c|}{} & \multicolumn{2}{|c|}{$\begin{array}{c}\text { Optimisation } \\
\text { algorithm } \\
\text { predictions }\end{array}$} & \multicolumn{2}{|c|}{$\begin{array}{c}\text { Actual } \\
\text { simulation } \\
\text { results }\end{array}$} & \multicolumn{2}{|c|}{ Error } \\
\hline $\begin{array}{c}\text { Disc } \\
\text { thickness } \\
(\mathrm{mm})\end{array}$ & $\begin{array}{c}\text { Coating } \\
\text { thickness } \\
(\mu \mathrm{m})\end{array}$ & $\begin{array}{c}\mathrm{Tc} \\
\left({ }^{\circ} \mathrm{C}\right)\end{array}$ & $\begin{array}{c}\mathrm{Ts} \\
\left({ }^{\circ} \mathrm{C}\right)\end{array}$ & $\begin{array}{c}\mathrm{Tc} \\
\left({ }^{\circ} \mathrm{C}\right)\end{array}$ & $\begin{array}{c}\mathrm{Ts} \\
\left({ }^{\circ} \mathrm{C}\right)\end{array}$ & $\begin{array}{c}\mathrm{Tc} \\
\left({ }^{\circ} \mathrm{C}\right)\end{array}$ & $\begin{array}{c}\mathrm{Ts} \\
\left({ }^{\circ} \mathrm{C}\right)\end{array}$ \\
\hline 12.24 & 30 & 472 & 443 & 473 & 445 & 0.42 & 0.46 \\
\hline
\end{tabular}

\section{Validation of the Optimum Results}

The optimum results obtained in the previous section were used to investigate the thermal performance of the coated disc brake rotor for a small sized vehicle $(1400 \mathrm{~kg})$ during two extreme braking events as follows:

1. Long continuous drag braking (extreme mountain descent) lasting $23 \mathrm{~min}$. Average slope of $12 \%$ and average vehicle speed of $80 \mathrm{~km} / \mathrm{h}$.

2. High rate constant g stop with a vehicle speed of $205 \mathrm{~km} / \mathrm{h}$ and deceleration of $1 \mathrm{~g}$.

The optimum value for the disc and coating thickness was used to simulate the two test conditions for the small scale wrought aluminium alloy rotor. The temperature distribution at the end of the extreme mountain descent is given in Figure 12. The results showed that the temperatures for the coating surface and the substrate were within the limits defined in the optimisation problem. This means that the optimisation results obtained indicate a good thermal performance for the coated aluminium alloy disc brake rotor under extreme drag braking conditions.

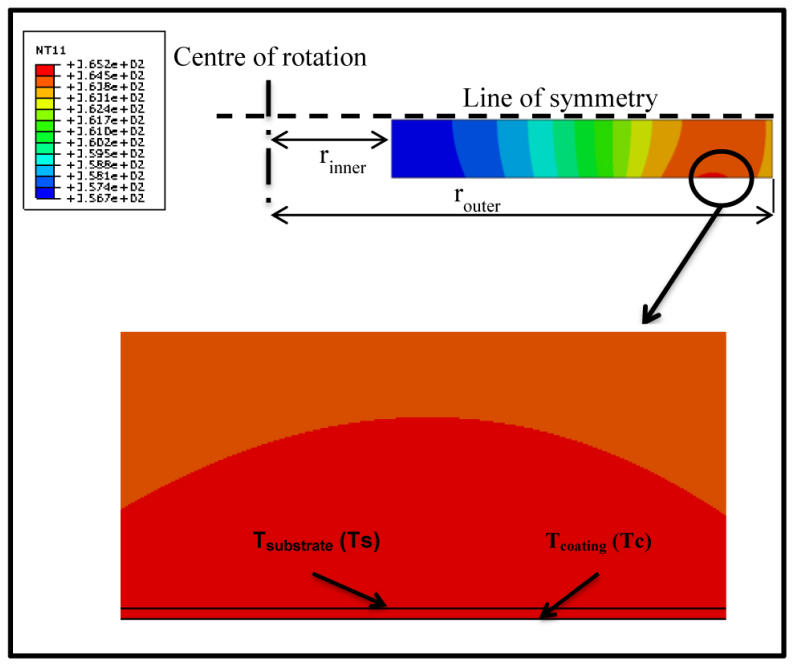

Figure 12. Temperature distribution of the coated small scale disc brake rotor at the end of simulation for the Alpine descent.

The same model was used with the second braking event, which was the high g stop. The temperature distribution during the test at different time steps is shown in Figure 13. In addition, the maximum surface temperature of the coating and substrate is shown in Figure 14 during and after the braking event. The results indicate that for the high g stop, the optimum disc brake model again shows good thermal performance and the temperature predicted is within the safe design limits for both the coating and substrate.

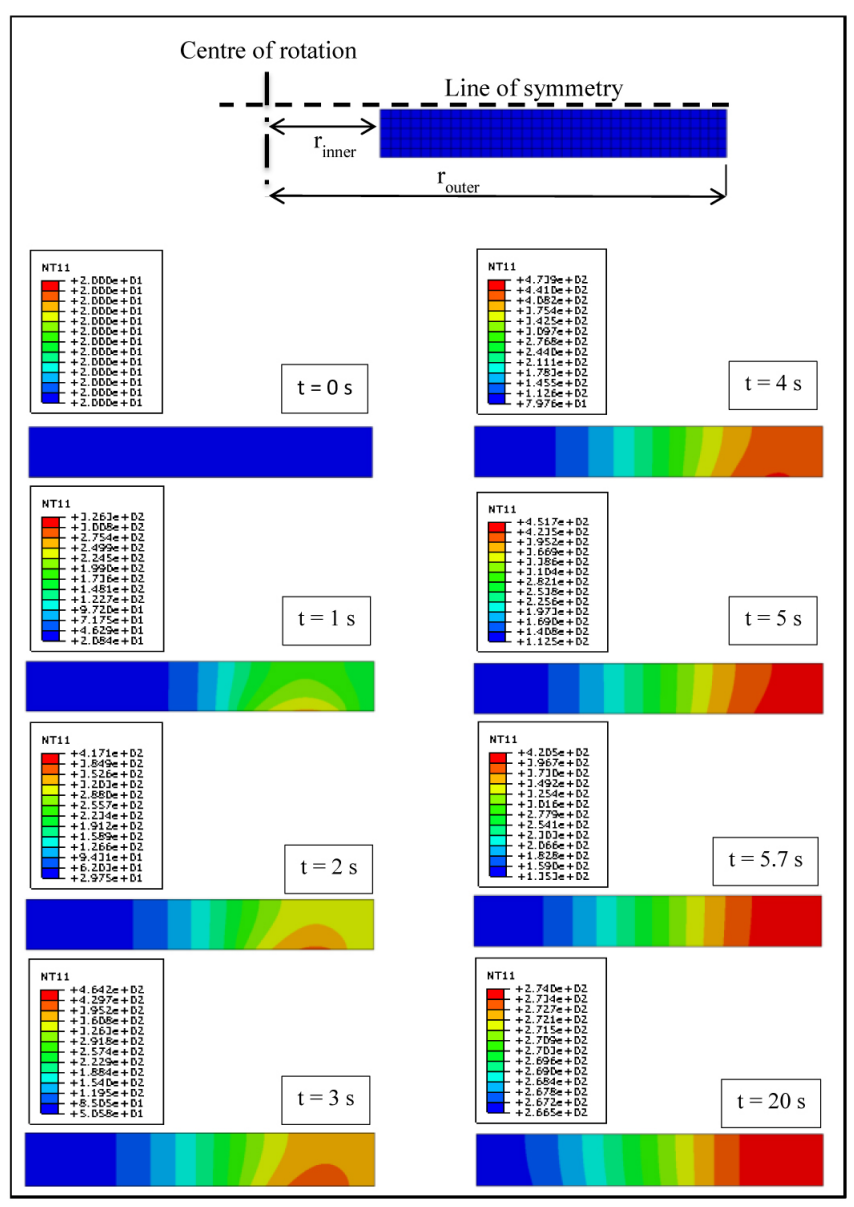

Figure 13. Temperature distribution of the coated small scale disc brake rotor for the high rate constant $\mathrm{g}$ stop.

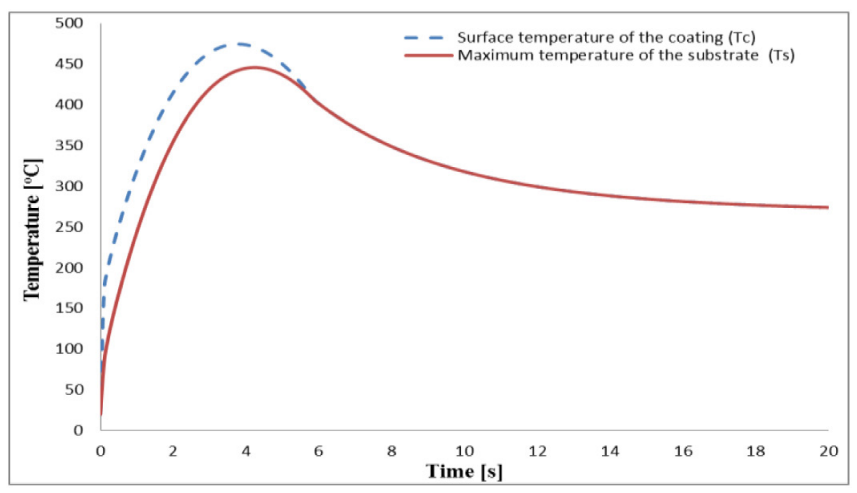

Figure 14. Maximum temperature responses on the coating and substrate surfaces during the high drag braking test.

\section{Conclusions and Future Work}

Experimental analysis of a coated small scale disc brake rotor thermal performance has shown that the maximum surface temperature of the coating prior to failure of the disc is of the order of $550^{\circ} \mathrm{C}$. Coating the whole disc brake limited the dissipation of energy by natural convection and trapped much of the heat inside the disc. This could be improved by coating the rubbing surface only to encourage the heat to dissipate by convection from all other surfaces.

A sensitivity analysis for the various brake rotor factors was undertaken using the Taguchi approach. The Taguchi analysis showed that substrate thickness has the largest effect on the 
predicted temperature distribution through the disc brake rotor. Material properties also have an influence on thermal performance but designing a material with specific thermal properties would be far from easy. The optimum design variables were found to be a coating thickness (tc) $=30 \mu \mathrm{m}$ and disc thickness $(\mathrm{ts})=12.24 \mathrm{~mm}$. The results show that this optimised design can withstand two different and very aggressive braking events for a vehicle of total mass $1400 \mathrm{~kg}$. The current optimisation analysis could be used with more complex disc brake geometry such as a ventilated rotor to allow greater heat loss by convection.

\section{References}

1. Alnaqi A., Barton D., and Brooks P., "Thermal Performance of Monolithic and Coated Disc Brakes Using Abaqus and Matlab Software," presented at SIMULIA Community Conference, Vienna, Austria, 2013.

2. Alnaqi A., Shrestha S., Brooks P., and Barton D., "Thermal Performance of PEO Coated Lightweight Brake Rotors Compared with Grey Cast Iron," Eurobrake 2014, France, 2014.

3. Alsaif M. A., Dahm K. L., Shrestha S., Dearnley P. A., and Barton D. C., "Plasma Electrolytic Oxidation (PEO) treated aluminium metal matrix composite rotors for lightweight automotive brakes," presnted at 6th European Conference on Braking, France, 2010.

4. Bozic G., Alnaqi A., Brooks P., and Barton D., "Thermal Characterisation of Lightweight Brake Rotors for Passenger Car Application Using A small Scale Brake Dynamometer and One Dimensional Model," Eurobrake 2012, Germany, 2012.

5. Dahm K. L., Black A. J., Shrestha S., and Dearnley P. A., "Plasma Electrolytic Oxidation treatment of aluminium alloys for lightweight disc brake rotors," IMechE Conference on Braking, York (UK), pp. 53-60, 2009.

6. Grieve D. G., Barton D. C., Crolla D. A., and Buckingham J. T., "Design of a lightweight automotive brake disc using finite element and Taguchi techniques," Proceedings of the Institution of Mechanical Engineers. Part D: Journal of Automobile Engineering, vol. 212(4), pp. 245-254, 1997, doi: $10.1243 / 0954407981525939$.

7. Neitzel, B., Barth, M., and Matic, M., "Weight Reduction of Disc Brake Systems with the Utilization of New Aluminum Material," SAE Technical Paper 940335, 1994, doi: $10.4271 / 940335$.

8. Wycliffe, P., "Friction and Wear of Duralcan Reinforced Aluminum Composites in Automotive Braking Systems," SAE Technical Paper 930187, 1993, doi:10.4271/930187.

9. Zhu, B., Barton, D., and Brooks, P., "Effects of Thermal Deformations on the Squeal Propensity of a Simple Automotive Disc Brake System," SAE Technical Paper 2008-01-2532, 2008, doi:10.4271/2008-01-2532.

10. Tonchev, A., Hirschberg, W., and Jagsch, S., "Investigation of the Thermal Vehicle Brake Behavior During the Vehicle's Development Phase by Co-Simulation," SAE Technical Paper 2007-01-3935, 2007, doi:10.4271/2007$\underline{01-3935}$.
11. Adamowicz, A., Grzes, P., "Analysis of disc brake temperature distribution during single braking under nonaxisymmetric load," Applied Thermal Engineering, vol. 31 issue 6-7 May, 2011, pp. 1003-1012, doi:10.1016/j. applthermaleng.2010.12.016.

12. Amin A. M., Seri S. M., and Raghavan V. R., "Study of the temperature distribution in disc brakes by the method of order-of-magnitude analysis," Regional Conference on Engineering Mathematics, Mechanics, Manufacturing \& Architecture, 2007.

13. Narayanan, A., Toropov, V. V., Wood, A. S., Campean, I. F., "Simultaneous model building and validation with uniform designs of experiments," Engineering Optimization, vol. 39 Issue 5, 2007, pp. 497-512, doi:10.1080/03052150701399978.

14. Abaqus CAE 6.11, Dassault Systèmes, Providence, RI, USA, Computer Software, 2011.

15. Taguchi G., "System of Experimental Design," American Suppliers Institute, INC, Dearborn, Michigan, ISBN-10: 0527916218, 1987.

16. Taguchi G., "Taguchi on Robust Technology Development," ASME Press, New York, ISBN-10: 0791800288, 1993.

17. Fowlkes W. Y. and Creveling C. M., "Engineering Methods for Robust Product Design: Using Taguchi Methods in Technology and Product Development," Corporate \& Professional Publishing Group, Reading, Massachusetts, ISBN-10: 0201633671, 1995.

18. Hyperstudy v12, Altair Engineering, Inc., Computer Software, 2012.

\section{Contact Information}

Abdulwahab Alnaqi

PhD student, School of Mechanical Engineering University of Leeds, West Yorkshire, LS2 9JT, UK

(tel) 44 (0) 7423278626

mnaaal@leeds.ac.uk

Suman Shrestha, Professor

Keronite International Ltd

Cambridge CB21 6GP, UK

suman.shrestha@keronite.com

David C. Barton, Professor

School of Mechanical Engineering

University of Leeds

West Yorkshire, LS2 9JT, UK

(tel) 44 113-343-2137

D.C.Barton@leeds.ac.uk

Peter C. Brooks, Senior Lecturer

School of Mechanical Engineering

University of Leeds

West Yorkshire, LS2 9JT, UK

(tel) 44 113-343-2122

P.C.Brooks@leeds.ac.uk 


\section{APPENDIX}

Table A1. Results of the $\mathrm{L}_{12}$ Taguchi study of the coated disc brake rotor.

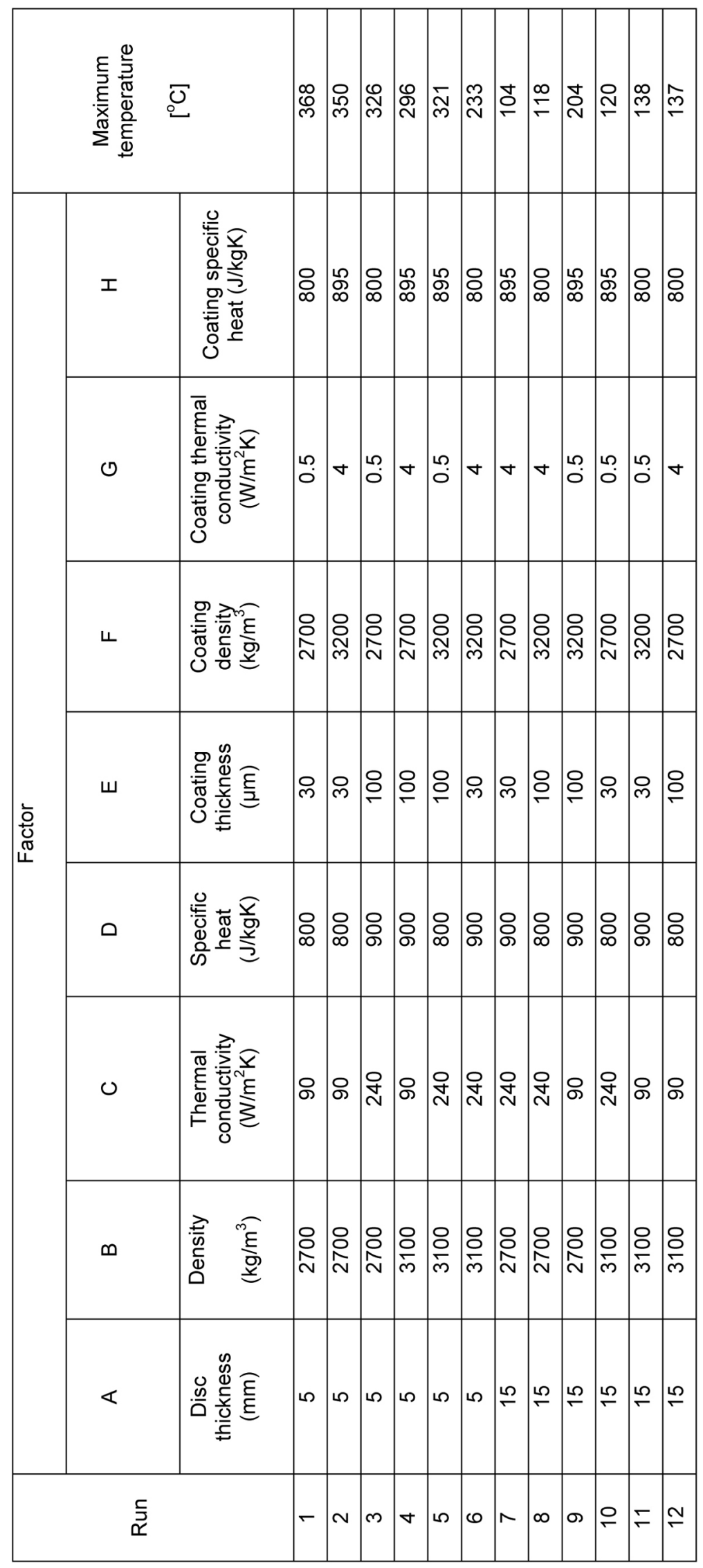


Table A2. S/N ratio and main effects for the coated disc brake rotor.

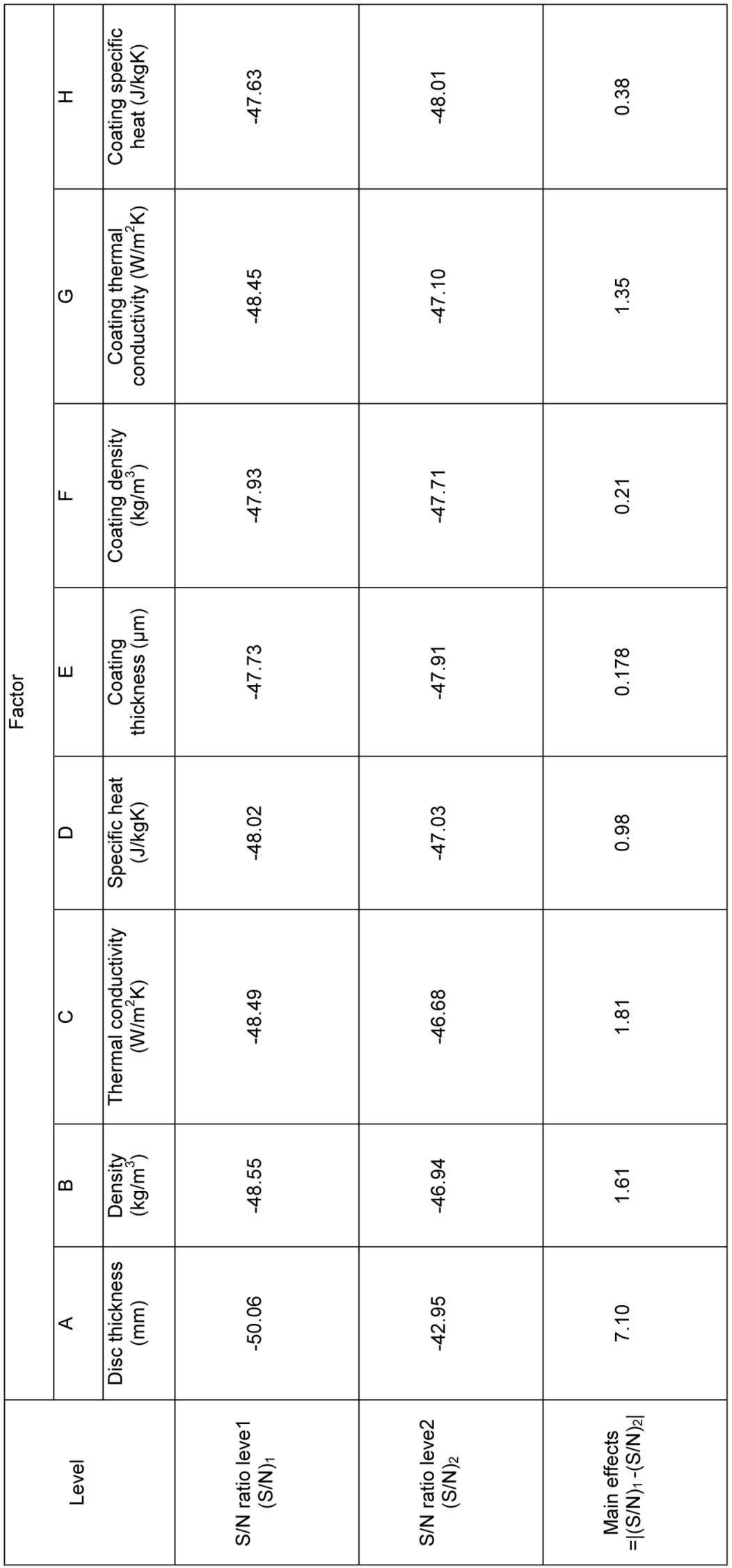


The Engineering Meetings Board has approved this paper for publication. It has successfully completed SAE's peer review process under the supervision of the session organizer. The process requires a minimum of three (3) reviews by industry experts.

All rights reserved. No part of this publication may be reproduced, stored in a retrieval system, or transmitted, in any form or by any means, electronic, mechanical, photocopying, recording, or otherwise, without the prior written permission of SAE International.

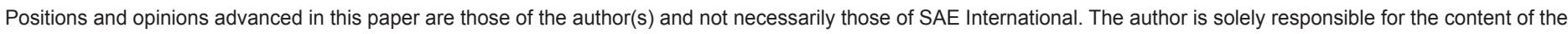
paper.

ISSN 0148-7191

http://papers.sae.org/2014-01-2501 